\title{
A IMPORTÂNCIA DA INCLUSÃO DIGITAL NO SISTEMA EDUCACIONAL
}

\section{ARTIGO ORIGINAL}

SILVA, Dijandira Francisca Ferreira da ${ }^{1}$, OLIVEIRA, Regis Flávio Varela de ${ }^{2}$

SILVA, Dijandira Francisca Ferreira da. OLIVEIRA, Regis Flávio Varela de. A importância da inclusão digital no sistema educacional. Revista Científica Multidisciplinar Núcleo do Conhecimento. Ano. 07, Ed. 02, Vol. 01, pp. 69-78. Fevereiro de 2022. ISSN: 2448-0959, Link de acesso: https://www.nucleodoconhecimento.com.br/educacao/importancia-dainclusao

\section{RESUMO}

As tecnologias têm um importante papel no sistema educacional. Sendo uma parceira de trabalho na educação, elas colaboram na apropriação de conhecimentos, tendo em vista que o saber é inacabado e sempre há algo novo para se aprender. Sabe-se que garantir o acesso ao saber é papel da escola, que deve democratizar o patrimônio cultural já existente. Diante disto, a escola, por meio da inclusão digital, pode capacitar mais cidadãos críticos, pensantes e preparados para enfrentar os desafios sociais da vida. Desta forma, a inclusão digital traz grandes benefícios no aspecto do sistema de ensino e aprendizagem. Neste contexto, o presente artigo, visa responder: Qual a importância da inclusão digital na educação? O objetivo da pesquisa é refletir sobre a importância da inclusão digital no sistema educacional. Tendo como metodologia bibliográfica, baseada em diferentes autores, que tratam da temática estudada. Os

1 Doutorado em Ciências da Educação (andamento); Mestrado em Ciências da Educação; Especialização em Psicopedagogia Clínica e Institucional; Graduação em Pedagogia. ORCID: 0000-0001-5349-8197

2 Orientador. ORCID: 0000-0003-1556-4717

RC: 106181

Disponível em: https://www.nucleodoconhecimento.com.br/educacao/importancia-da-inclusao 
resultados apontaram que a demasiada oferta de informação pode causar saberes não sistematizados, sendo a escola responsável pela sistematização desse saber. Por isso, a educação e as tecnologias, precisam caminhar juntas para a expansão e a organização do saber. Concluiu-se, também, que na era da informação é essencial a utilização das tecnologias de informação na construção do conhecimento, para atender as necessidades atuais dos alunos, em meio aos avanços tecnológicos. Sendo de fundamental importância a inclusão das tecnologias na educação para uma aprendizagem significativa e estreitamento de informações entre os educandos, para o incremento de habilidades e desenvolvimento social.

Palavras-Chaves: Educação, tecnologia, ensino, aprendizagem.

\section{INTRODUÇÃO}

A inclusão das tecnologias no sistema educacional é de fundamental importância, já que o mundo está em constante mudanças e a era digital é uma realidade dos indivíduos em processo de aprendizagem na educação (LIBÂNEO, 2000; 2007; LEVY, 1993).

O avanço tecnológico tem tomado espaço na sociedade. A inclusão desse meio de conhecimento tem se tornado cada vez mais necessária no cotidiano das pessoas, especialmente nas escolas, de forma que, os conhecimentos sejam aproveitados e aprimorados.

Por meio das situações e experiências vividas por cada indivíduo, ao longo da sua vida, a educação vai se desenvolvendo. Portanto, a educação prepara o indivíduo para a vida, como afirma Freire (1991). Por isso, sente-se a necessidade da inclusão digital nas escolas, como forma de sustentar e aprimorar esses saberes surgidos ao longo do tempo.

$\mathrm{Na}$ era digital e na perspectiva do novo, as tecnologias trazem importantes colaborações para a prática pedagógica e o sistema educacional, demostrando a

RC: 106181

Disponível em: https://www.nucleodoconhecimento.com.br/educacao/importancia-da-inclusao 
importância da atualização dos conhecimentos para acompanhar a sociedade em suas constantes mudanças.

Neste contexto, o presente artigo, tem como questão norteadora: Qual a importância da inclusão digital na educação? A inclusão digital harmoniza um espaço lúdico e dinâmico na aprendizagem dos alunos, facilitando o processo de ensino e aprendizagem.

As escolas têm o papel de formar alunos direcionados para a vida, e as tecnologias podem ser aliadas nesse processo ativo de aprendizagem, já que as mesmas são responsáveis por grande fonte de saber que, se usadas sistematicamente, podem trazer grandes benefícios para a sociedade.

Portanto, o objetivo deste artigo é refletir sobre a importância da inclusão digital no sistema educacional. Tendo como objetivos específicos estudar: a educação e as tecnologias de informação; o ensino na era digital e a inclusão tecnológica no processo de aprendizagem.

Para isto, adotou-se como metodologia a pesquisa bibliográfica, baseada em diferentes autores, que tratam da temática estudada.

\section{A EDUCAÇÃO E AS TECNOLOGIAS DE INFORMAÇÃO}

A educação tem importante papel na sociedade. Além de transmitir conhecimentos, ela tem compromisso com a formação de cidadãos, preparando os alunos para a vida. $E$ isso advém da promoção do desenvolvimento socioeducativo e do melhor acesso à informação, sendo o uso da tecnologia um fator fundamental na interação escolar.

Lévy (1993) afirma que as tecnologias precisam ser inseridas no ambiente escolar, já que elas têm papel fundamental no estabelecimento dos referenciais intelectuais e espaço-temporais da sociedade.

RC: 106181

Disponível em: https://www.nucleodoconhecimento.com.br/educacao/importancia-da-inclusao 
A inclusão das tecnológicas nas escolas trás mudanças e incrementos ao saber. Quando os indivíduos têm acesso aos conhecimentos digitais, aprendem com o saber do outro e compartilham aprendizados distintos, ocorrendo redes de interações e experiências, interferindo, assim, no desenvolvimento das pessoas.

Libânio (2000) afirma que a escola deve possibilitar a inclusão das tecnologias nas salas de aula no intuito de aprimorar a comunicação e os saberes significativos da cultura e ciência entre os agentes da ação docente e discente.

Portanto, a interação entre a educação e as tecnologias é de suma importância para aprendizagem, tanto dos educandos como dos professores, que aprendem ensinado e compartilhando conhecimentos.

Ries; Rocha e Silva (2020) apresentam que o ato de ensinar e aprender promove o repensar da prática pedagógica e o enfrentamento de desafios de forma corresponsável na construção de ensino e aprendizagem. Demonstrando que as novas estratégias educacionais precisam estar ligadas as metas a cumprir.

Inserir tecnologias no ambiente escolar é procurar novas estratégias de ensino, visando uma educação melhor. Sendo fundamental que a educação reflita e trabalhe com os professores e alunos a inclusão digital de forma positiva e sistematizada, para que o conhecimento venha a ser satisfatório e proveitoso. A tecnologia complementa os conhecimentos dos envolvidos na prática educativa, trazendo benefícios para a aprendizagem.

\section{O ENSINO NA ERA DIGITAL}

O ensino na era digital é um desafio. Portanto, propor estratégias diferenciadas usando as tecnologias de informação como aliadas da educação é um método eficaz para o processo de ensino e aprendizagem. Verifica-se que a inclusão digital se tornou uma necessidade nas salas de aula, pois, além de tratar de questões reais dos alunos, torna a aula mais desafiante, reflexiva, prática e dinâmica.

RC: 106181

Disponível em: https://www.nucleodoconhecimento.com.br/educacao/importancia-da-inclusao 
Para educar na era da informação ou na sociedade do conhecimento é necessário extrapolar as questões de didática, dos métodos de ensino, dos conteúdos curriculares, para poder encontrar caminhos mais adequados e congruentes com o momento histórico em que estamos vivendo. (MORAES, 1999, p. 27).

Nesse contexto, o uso das tecnologias como instrumento pedagógico necessita estar fundamentado em sugestões pedagógicas planejadas e baseadas em entendimentos que consintam a aplicabilidade de tecnologias inovadoras que potencializem 0 processo de ensino e tornem a aula mais atrativa, interativa e sistematizada, contribuindo para um processo de ensino proativo.

Pereira (2009) afirma que a prática educativa é uma atividade social, que visa o ensino de conhecimentos, tanto científicos como culturais. Sendo um exercício que trabalha a realidade social do indivíduo. Portanto, a inclusão das tecnologias nas escolas é de fundamental importância, auxiliando no processo de ensino, o que traz grandes benefícios para a educação, pois estas auxiliam no processo de assimilação dos alunos dos conteúdos trabalhados em sala de aula e envolvem os conhecimentos de forma prática e dinâmica.

Diante da era da informação, onde as tecnologias têm se tornado instrumento fundamental no processo de ensino e aprendizagem, é preciso, portanto, que as escolas se reinventem e as incluam em seus planejamentos escolares, pois a inclusão só acontece de fato, quanto se é pensado as possibilidades e estudado a realidade, para, assim, executar a prática educativa.

Com o crescente desenvolvimento tecnológico, vivemos uma civilização em tempos de mudança, na qual os meios de comunicação social tornaram-se onipresentes, determinando cada vez mais comportamentos, atitudes, valores e estilos de vida. Imersos em um universo audiovisual, cada vez mais complexo, crianças e jovens devem assimilar e reacomodar seus códigos comunicacionais para captar o ritmo vertiginoso e as mudanças que a realidade lhes impõe. (PACHECO, 1991, p. 09).

A sociedade está em constantes mudanças e, na ânsia de procurar respostas, buscar fontes de conhecimentos para acompanhar o ritmo da geração atual, as tecnologias,

RC: 106181

Disponível em: https://www.nucleodoconhecimento.com.br/educacao/importancia-da-inclusao 
se encontram como um importante instrumento do conhecimento, colaborando para o surgimento de um novo modelo educacional com a inclusão destas.

A acessibilidade de informação e as constantes direções de conhecimento, alteram as estruturas da organização e funcionamento do sistema de ensino. Trazendo as instituições educacionais desafios, não apenas no sentido de incluir as novas tecnologias em seus conteúdos de ensino e reconhecer as percepções dos alunos sobre estas, mas também, no sentido de elaborar, desenvolver e avaliar práticas pedagógicas que gerem o desenvolvimento do saber por meio das tecnologias. Portanto, para o emprego coerente das ferramentas digitais, que em alguns casos não são compreendidas pela maioria dos educandos e docentes de forma coerente e sistematizada, é preciso que o professor esteja familiarizado com as tecnologias, para ensinar e, os educandos, estejam dispostos a aprender a utilizar essas ferramentas em favor da ciência.

Segundo Valente (2011), o ensino e a aprendizagem precisam estar relacionados com a realidade social atual, atentando-se a informação que deve ser acessada e o conhecimento que precisa ser construído pelo educando.

Diante das necessidades da sociedade atual, é necessário incluir as tecnologias no ambiente escolar, pois estas se tornaram um artifício de aquisição do conhecimento, necessitando de um novo olhar crítico do sistema educacional, que precisa entender a realidade social do indivíduo na era digital e criar estratégias para acompanhar essas mudanças, compreendendo que as novas tecnologias abrem novas possibilidades na educação, demandando uma nova postura do professor.

\section{A INCLUSÃO TECNOLÓGICA NO PROCESSO DE APRENDIZAGEM}

A escola exerce papéis essenciais na sociedade. Tem função de socializar e democratizar o acesso ao conhecimento e promover a construção moral e ética dos educandos, promovendo a formação de indivíduos críticos, colaborando para uma 
transformação pessoal e social, possibilitando a inclusão digital no intuito de favorecer a aprendizagem dos alunos.

Libâneo (2007) afirma que a os envolvidos no processo de aprendizagem não podem ignorar a presença das tecnologias, sabendo da sua importância na sala de aula e na construção do saber.

As tecnologias têm sido uma necessidade nas escolas. À medida que a sociedade se aperfeiçoa, surgem novas conhecimentos e diferentes ferramentas no auxílio do processo de aprendizagem.

De acordo com Neto (2017), as constantes modernizações digitais têm grande influência na sociedade. Sendo essencial a inclusão destas no processo de apropriação do conhecimento.

A educação no mundo de hoje tende a ser tecnológica, por isso, exige entendimento e interpretação, tanto dos professores quanto dos alunos. O uso da tecnologia no ambiente escolar, acarreta diversos sentimento em relação a postura dos professores frente a novos desafios, seja a satisfação de estar participando de uma realidade tecnológica ou a ansiedade por enfrentar novas mudanças.

A inclusão digital na educação é importante, pois, além de tratar de meios de interações de conhecimentos, facilita e motiva o processo de aprendizagem, que requer meios inventivos e troca de saberes, proporcionando a participação ativa dos alunos nas atividades escolares.

Valente (1999) afirma que o exercício pedagógico deve envolver o aluno, o professor, os recursos disponíveis, inclusive as tecnologias digitais, e todas as interações que se estabelecem no ambiente escolar.

Para que aconteça o desenvolvimento de aprendizagem dos alunos no sistema educacional, é necessário que haja uma boa relação educacional com recursos 
tecnológicos. Não é suficiente ter os recursos, é preciso que eles sejam bem utilizados para produção de uma aprendizagem consistente e organizada.

A escola é um local de ressignificação dos conteúdos, promovendo a interação e aproximação dos laços com a comunidade. Desta forma, pode-se compreender a realidade dos alunos e procurar estratégias de intervenção inserindo as tecnologias no processo de aprendizagem. Sendo o cenário atual caracterizado pela era digital, a escola não pode deixar de atender as exigências da atualidade, que necessitam de utensílios digitais, para o benefício do trabalho realizado em sala de aula.

Conforme aponta Cesar (2020), as estratégias do poder público devem lançar mão de ações que procurem reduzir o risco das desigualdades educacionais. Portanto, todos os alunos devem ter acesso à internet, para estarem conectado com o mundo.

Portanto, o acesso e um bom planejamento para a inclusão digital no sistema educacional, possibilitam o contato com diferentes culturas, o compartilhamento e multiplicação de conhecimentos. É preciso criar uma sociedade mais justa, onde todos tenham acesso às informações. Portanto, é importante que a escola crie meios para incluir as tecnologias e todos os alunos possam participar da construção do saber tecnológico.

Valente (2003) afirma que as tecnologias de informação criam aprendizagem com interação de vários conceitos, possibilitando um saber ampliado, com várias contribuições sociais.

Requerer a acessibilidade e envolver a seriedade da inclusão digital, é eficaz para que todas as pessoas, abrangendo todas as classes sociais, tenham acesso às informações e as facilitações trazidas pelo uso da tecnologia, criando um espaço educacional mais participativo, onde todos possam ter acesso à rede digital e se aprofundar no conhecimento. 
As novas tecnologias precisam estar conectadas com o conhecimento sistematizado para uma aprendizagem significativa. Aliada a escola, elas serão de grande valia. Portanto, a interatividade precisa ser feita de forma consciente e responsável, para que os educandos entendam a importância tecnológica e façam boa utilização desses meios.

\section{CONSIDERAÇÕES FINAIS}

Por fim, retomando a questão norteadora: Qual a importância da inclusão digital na educação? Concluiu-se que a inclusão digital é de fundamental importância no sistema educacional, pois além de facilitar a busca pelo conhecimento, estimula o processo de ensino e aprendizagem, promovendo a participação ativa do aluno. As tecnologias em parceria com a educação proporcionam um espaço mais atrativo e dinâmico para professores e alunos, estimulando o prazer em construir e compartilhar saberes.

A educação vai além da transmissão teórica do conhecimento de conteúdos curriculares, tem importante papel na contribuição da formação dos educandos e promoção da transformação social. Desta forma, utilizar as ferramentas digitais, que já são uma realidade do aluno, auxilia na organização e construção de um saber sistemático e científico.

Diante dos grandes avanços da atualidade, percebe-se que a influência que as tecnologias exercem no campo educacional, sendo preciso, portanto, que as escolas busquem a implementação das informações digitais para aprimorar o processo de ensino e aprendizagem.

Com o uso tecnológico é possível planejar aulas diversificadas para os educandos, oferecendo a oportunidade de aprenderem com o novo, respeitando as particularidades de cada um. Portanto, a escola é um ambiente de interação, que agregado as tecnologias permite fazer a ponte entre o conhecimento, tornando-se componente de cooperações e transformações sociais.

RC: 106181

Disponível em: https://www.nucleodoconhecimento.com.br/educacao/importancia-da-inclusao 


\section{REFERÊNCIAS}

CESAR, N. Ensino a distância na educação básica frente a pandemia da covid19. Todos pela Educação (TPE); instituto Inspirare, 2020. Disponível em: Educação na pandemia: ensino a distância da importância solução emergencial, mas resposta à altura exige plano para volta as aulas/ Todos pela Educação (todospelaeducação.org.br). Acesso em: 18 out. 2021.

FREIRE, Paulo. A Educação na cidade. São Paulo: Cortez, 1991.

LÉVY, Pierre. As tecnologias da inteligência: o futuro do pensamento na era da informática. Rio de Janeiro: Editora 34, 1993.

LIBÂNEO, José Carlos. Adeus professor, adeus professora? Novas exigências educacionais e profissão docente. $4^{\mathrm{a}}$ ed. São Paulo: 2000.

LIBÂNEO, José Carlos. As tecnologias da comunicação e informação e a formação de professores. In: SILVA, Carlos Cardoso, SUANNO, Marilza Vanessa Rosa (Org.). Didática e interfaces. Rio de Janeiro: Goiânia, 2007.

MORAES; M. C. O Paradigma Educacional Emergente. Campinas: papiros, p.27; 1999.

NETO, E. B. O Ensino híbrido: processo de ensino mediado por ferramentas tecnológicas. São Paulo: Ponto e Vírgula, n. 22, 2017.

PACHECO, Elza Dias (org.). Comunicação, Educação e Arte na Cultura Infantojuvenil. São Paulo: Loyola, p. 09, 1991.

PEREIRA, Antônio. A educação social de rua é uma práxis educativa? Revista Ciências da Educação. São Paulo: UNISAL -Americana, ano XI, N. 21, 2009. 
RIES, E. F.; ROCHA, V. M. P.; SILVA, C. G. L. Avaliação do ensino remoto de Epidemiologia em uma universidade pública do Sul no Brasil durante pandemia de COVID-19. UFSM: Santa Maria, p. 1-20, 2020.

VALENTE, J. A. Repensando situações de aprendizagem: fazer e compreender. Artigo Coleção Série Informática na educação. Editora: Avercamp, 2003.

VALENTE, J. A. (Org.) O computador na sociedade do conhecimento. Campinas: Unicamp-niesd, 1999.

VALENTE, J. A. Educação à Distância: pontos e contrapontos. São Paulo: Summus, 2011.

Enviado: Janeiro, 2022.

Aprovado: Fevereiro, 2022. 